De paseo por un museo Virtual. Aprendizajes y Valoraciones de estudiantes universitarios. Páginas $79-98$ en

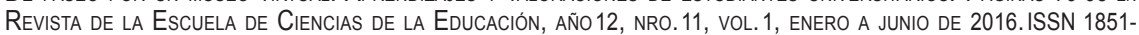
6297. ISSN EN LÍNEA 2362-3349.

\title{
DE PASEO POR UN MUSEO VIRTUAL. APRENDIZAJES Y VALORACIONES DE ESTUDIANTES UNIVERSITARIOS
}

\author{
María Fernanda Melgar* \\ Universidad Nacional de Río Cuarto, Argentina. \\ fernandamelgar@gmail.com \\ Analía Claudia Chiecher** \\ Universidad Nacional de Río Cuarto, Argentina. \\ achiecher@hotmail.com
}

Recibido: 14/03/2016 Aceptado: 04/04/2016

\section{Resumen}

La educación es una de las funciones reconocida de los museos. Focalizamos en el presente artículo en los museos virtuales, entendidos como contextos de aprendizaje. Presentamos un estudio que propuso la participación de estudiantes universitarios en experiencias que involucraron la visita a museos virtuales del Google Cultural Institute. Participaron de la investigación 38 estudiantes universitarios quienes, distribuidos en grupos, debían dar respuesta a una tarea académica, luego de la visita a un museo virtual. Los datos que presenta el artículo fueron recogidos mediante la administración de dos cuestionarios, ambos de preguntas abiertas. Uno de ellos fue administrado antes de la realización de la tarea en tanto que el otro fue respondido una vez finalizada. El

* Licenciada en Psicopedagogía por la Universidad Nacional de Río Cuarto, Argentina. Máster en Psicología de la Educación por la Universidad de Murcia, España. Doctora en Psicología por la Universidad Nacional de San Luis, Argentina. Becaria Posdoctoral del Consejo Nacional de Investigaciones Científicas y Técnicas. Profesora Ayudante de Primera en la Facultad de Ciencias Humanas de la Universidad Nacional de Río Cuarto.

** Licenciada en Psicopedagogía y Magíster en Educación y Universidad, por la Universidad Nacional de Río Cuarto, Argentina. Doctora en Psicología por la Universidad Nacional de San Luis, Argentina. Investigadora Adjunta Consejo Nacional de Investigaciones Científicas y Técnicas y docente en la Universidad Nacional de Río Cuarto. Es directora de becarios doctorales y posdoctorales de CONICET. Docente en cursos de posgrado. 
Revista de la Escuela de Ciencias de la Educación, año 12, nRo.11, vol. 1, enero a junio de 2016. Páginas 79-98. ISSN 1851-6297. ISSN EN LÍNEA 2362-3349. DE PASEO POR UN MUSEO VIRTUAL. APRENDIZAJES Y VALORACIONES DE estudiantes universitarios. María Fernanda Melgar - Analía Claudia Chiecher

primero se orientaba a sondear concepciones de los estudiantes acerca de los museos virtuales mientras que el segundo apuntó a captar las valoraciones de los sujetos acerca del museo virtual visitado, desde sus dimensiones física, social y personal. Entre los principales resultados identificamos concepciones sobre los museos virtuales y sus funciones así como aspectos físicos, sociales y personales destacados en la configuración de los museos virtuales como contextos educativos. Las conclusiones destacan las potencialidades de los museos virtuales como contextos para aprender.

\title{
Palabras clave:
}

Museos - Aprendizaje - TIC - Experiencias - Universidad.

\begin{abstract}
Education is one of the recognized functions of museums. We focus in this article on virtual museums, understood as learning contexts. We present a study that proposed the participation of university students in experiences that involved visiting virtual museums in the Google Cultural Institute. They participated in the study 38 university students who, divided into groups, had to respond to an academic task, after visiting a virtual museum. The data presented in the article were collected by administering two questionnaires, both of open questions. One of them was administered before performing the task while the other was answered when completed. The first was aimed to probe students' conceptions about virtual museums while the second aimed to capture the valuations of subjects about the virtual museum visited, since their physical, social and personal dimensions. Among the main results we identify conceptions of virtual museums and their functions as well as featured in the configuration of virtual museums as educational contexts physical, social and personal aspects. The findings highlight the potential of virtual museums as contexts for learning.
\end{abstract}

\section{Keywords:}

Museums - Learning - TIC - Experience - University.

\section{Museos y aprendizaje}

\subsection{Contextos y aprendizaje}

Desde mediados del siglo XX, el Consejo Internacional de Museos (ICOM), destaca en la definición de esta institución su función educativa. Señala que los museos son instituciones abiertas al público y al servicio de la sociedad, que adquieren, conservan, investigan, comunican y exhiben, el patrimonio material e inmaterial, con propósitos de educación y deleite.

Pensar los museos como espacios de educación, implica pensar en el aprendizaje. Los museos constituyen contextos de educación no formal e informal, que tienen un papel destacado en la formación integral de las personas, en la promoción de procesos de conocimiento, conformación de la identidad 
Revista de la Escuela de Ciencias de la Educación, año12, nRo.11, vol. 1, enero a Junio de 2016. PÁginas 79-98. ISSN 1851-6297. ISSN EN LINEA 2362-3349. DE PASEO POR UN MUSEO VIRTUAL. ApRENDIZAJeS Y VAloRACIONES DE estudiantes universitarios. María Fernanda Melgar - Analía Claudia Chiecher

colectiva, en la formación científica, en el respeto y valoración del patrimonio integral, en la formación ciudadana del público.

Los aportes de los enfoques socio-constructivistas del aprendizaje caracterizan a este constructo como un proceso personal, social, contextualizado, temporal, múltiple, situado y distribuido. Es un proceso personal que supone el compromiso de quien aprende. Aprender es una elección, un proceso basado en las experiencias afectivas, cognitivas, conductuales y sociales de las personas y sus posibilidades de conectarlas con nuevas experiencias (Rennie y Johnston, 2004).

Es un proceso social; a través de la interacción con otros las personas averiguamos de qué trata y cómo se concibe el mundo (Bruner, 1997; Cole, 1999). Es una actividad social, inseparable de las relaciones con otros (Alderoqui, 2011).

Es un proceso contextualizado; tiene lugar en muchos entornos, se produce en las aulas y laboratorios, en los entornos virtuales y ambientes naturales, en los lugares de trabajo y sitios donde se realiza una actividad comunitaria. Cada aprendizaje debe estar construido de tal manera que permita que los sujetos puedan emplearlos en los momentos que los necesitan (Lemke, 2006).

Es un proceso temporal; si entendemos el aprendizaje como un cambio, debemos reconocer que éste no es súbito, ni instantáneo, sino que supone un tiempo en el que el sujeto pueda establecer nuevas relaciones entre su bagaje de conocimientos y las nuevas oportunidades, por ejemplo, brindadas por el museo (Rennie, 2007; Lemke, 2006).

Es un proceso múltiple; tiene lugar a través del empleo de una variedad de soportes. Aprendemos por medio de representaciones visuales que elaboramos a partir de diferentes portadores (dibujos, mapas, fotos, películas y vídeos, simulaciones 3D, etc.); observando y participando en actividades; aprendemos integrando significados a través de todas estas modalidades. Pero esta integración no es automática o natural, es culturalmente específica y debe ser enseñada y aprendida (Lemke, 2006).

Es un proceso situado; lo situado del aprendizaje hace referencia a que la educación no es el producto de procesos cognitivos individuales sino de la forma en que tales procesos se ven conformados en la actividad por un grupo de elementos que se ponen en juego, tales como las percepciones, significados, interacciones, recursos y elecciones. Estos aspectos son el resultado de una relación dinámica que se establece entre quien aprende y el entorno sociocultural en el que se ejerce la acción o actividad (Sagástegui, 2004).

Es un proceso distribuido. La cognición no se encuentra contenida dentro de la mente, sino que se distribuye en sistemas que la conectan con aspectos del contexto físico y social. Una concepción del aprendizaje como un proceso distribuido considera que la inteligencia no es una posesión individual sino que 
Revista de la Escuela de Ciencias de la Educación, año12, nRo.11, vol.1, enero a Junio de 2016. Páginas 79-98. ISSN 1851-6297. ISSN EN LÍNEA 2362-3349. DE PASEO POR UN MUSEO VIRTUAL. APRENDIZAJeS Y VALORACIONES DE estudiantes universitarios. María Fernanda Melgar - Analia Claudia Chiecher

se ejecuta en la asociación y conjunción de la mente del sujeto, los artefactos culturales y otros sujetos (Perkins, 1993).

Desde esta concepción del aprendizaje, los museos pueden constituirse, sin dudas, en contextos poderosos y creativos para aprender. En este sentido, tanto las prácticas desarrolladas por museos en sus edificios como aquellas que se realizan aprovechando las potencialidades de los entornos virtuales, resultan de interés para la promoción de aprendizajes.

Los contextos poderosos promueven el aprendizaje activo y constructivo en el marco de situaciones reales. Estimulan la participación de las personas, propician oportunidades para trabajar activamente en el logro de nuevos conocimientos que pueden concretarse a través de las tareas académicas. Los contextos poderosos consideran la calidad del conocimiento, los tipos de lenguajes, discursos y herramientas que circulan, los procesos de feedback, las oportunidades para la colaboración entre pares y el carácter de las evaluaciones (Rinaudo, 2014). En los contextos poderosos, la participación se traduce en experiencias. En este sentido, los museos se presentan como contextos poderosos para generar experiencias variadas y alternativas. A través de sus propuestas pueden generar experiencias únicas que impactan en la formación de las personas. La educación en los museos es esencialmente un proceso de construcción de significados, que involucra la negociación entre las historias que los museos cuentan y aquellas que traen los visitantes (Alderoqui, 2011).

Los museos ofrecen ocasiones para la creatividad (Elisondo, Donolo y Rinaudo, 2009). Permiten interactuar con artefactos culturales y vivenciar experiencias significativas de aprendizaje. Muestran mundos, culturas y producciones culturales diferentes. Cuentan historias y abren espacios para la imaginación. En suma, entendemos a la creatividad como proceso socio-cultural y a los museos como entornos que promueven interacciones con conocimientos, artefactos culturales, personalidades, contextos e historias. Entonces, consideramos a los museos espacios propicios para la creatividad y el aprendizaje (Elisondo y Melgar, 2015).

\subsection{El Modelo Contextual del Aprendizaje en museos}

El Modelo Contextual del Aprendizaje (en adelante MCA) es una propuesta teórica que permite pensar en la singularidad del aprendizaje en los museos, en su diferenciación respecto a otros entornos y contextos, en virtud de su naturaleza única. Se trata de un proceso que se produce en la interacción y diálogo de las personas con sus entornos, es dinámico y está atravesado por la dimensión temporal. EI MCA considera que a la hora de diseñar y analizar el aprendizaje en los museos es necesario tener en cuenta ocho factores que se presentan en cada uno de los contextos personal, sociocultural y físico. 
Revista de la Escuela de Ciencias de la Educación, año12, nRo.11, vol. 1, enero a Junio de 2016. PÁginas 79-98. ISSN 1851-6297. ISSN EN LINEA 2362-3349. DE PASEO POR UN MUSEO VIRTUAL. ApRENDIZAJeS Y VAloRACIONES DE estudiantes universitarios. María Fernanda Melgar - Analía Claudia Chiecher

\subsubsection{El contexto personal}

Refiere a aspectos que se vinculan con las características singulares de las personas, su estructura de conocimiento y experiencias previas, sus motivaciones, sus intereses, sus afectos, sus creencias y las características sociodemográficas entre otros. Dentro del contexto personal los autores identifican tres factores: motivación y expectativas; los conocimientos previos, intereses y creencias y las oportunidades de elección y control.

Motivación y expectativas. Las personas que van a los museos lo hacen por diversos motivos, ellas tienen una variedad de expectativas que influyen directamente sobre lo que se aprende. Cuando las expectativas se satisfacen, se facilita el aprendizaje. Los museos que consideren los aspectos motivacionales de sus visitantes deben saber que las personas pueden estar altamente motivadas para aprender cuando son apoyadas por el ambiente, cuando se comprometen en actividades significativas, cuando están libres de ansiedad y miedo y; cuando ellos eligen y tienen control sobre su aprendizaje (Falk y Dierking, 2000; Hervás Avilés, 2010).

Los conocimientos previos, los intereses y las creencias. Las personas seleccionan de una manera activa qué tipo de museos visitar, qué exposiciones ver, en qué programas participar y a qué aspectos de la experiencia prestar atención. El sentido de la experiencia educativa en un museo se enmarca dentro de los conocimientos previos, intereses y creencias de los visitantes; de allí su carácter altamente personal.

Cuando a las personas les gusta algo, atribuyen sentimientos positivos y valores a eso y el resultado es una alta probabilidad de que elegían seguir haciéndolo. Una acción que puede fluir desde el interés es la decisión de visitar un museo o participar de una exhibición específica. Un amplio número de investigaciones han remarcado la presencia del afecto (sentimientos, actitudes, emociones) en el aprendizaje y en la conducta que ocurre en ambientes como el museo (Falk y Dierking, 2000).

La elección y el control. Las actividades que promueven en las personas un sentimiento de control sobre sus resultados tienen el potencial de generar motivación intrínseca. Los sujetos tienden a comprometerse en actividades en las que ellos perciben alguna relación entre sus acciones y los resultados obtenidos. La elección es la habilidad para seleccionar entre cursos de acciones posibles y la libertad para elegir el nivel de esfuerzo a desplegar en relación con un propósito particular. El interés que una persona manifiesta en un tema, en una tarea o en una actividad específica se relaciona con sentimientos positivos de disfrute e implicación. En relación con el aprendizaje en museos Hervás Avilés (2010) señala que estas instituciones a menudo ofrecen abundantes oportunidades tanto para la libre elección como para la autorregulación. 
Revista de la Escuela de Ciencias de la Educación, año12, nRo.11, vol. 1, enero a Junio de 2016. Páginas 79-98. ISSN 1851-6297. ISSN EN LÍNEA 2362-3349. DE PASEO POR UN MUSEO VIRTUAL. APRENDIZAJeS Y VALORACIONES DE estudiantes universitarios. María Fernanda Melgar - Analia Claudia Chiecher

\subsubsection{El contexto sociocultural}

Durante las visitas a museos las interacciones sociales ocurren constantemente. La facilitación sociocultural es un aspecto característico del aprendizaje en los museos. Falk y Dierking (2000) señalan que esta facilitación puede ser entendida de dos maneras: como mediación sociocultural dentro de un grupo y como mediación facilitada por otros.

La mediación sociocultural dentro de un grupo. Se entiende a aquellas visitas que se realizan al museo formando parte de algún grupo con el que se comparten ciertas características por ejemplo: compañeros de clase, familia, grupos de amigos, grupo de turistas, entre otros. La mayoría de los visitantes van a los museos en grupos que comparten una historia y que forman comunidades de aprendices. Los padres ayudan a sus hijos a comprender y dar sentido a sus experiencias. Los niños aportan sus nuevas formas de ver las cosas, los compañeros crean vínculos sociales a través de experiencias y conocimientos compartidos. La interacción entre miembros de un grupo o entre grupos en los museos permite comprender la información y reforzar las creencias compartidas (Falk y Dierking, 2000).

La mediación facilitada por otros. El aprendizaje socialmente mediado en los museos no sólo ocurre dentro de un grupo social, puede producirse entre personas que sin conocerse interaccionan y se reconocen compartiendo experiencias educativas. Muchas de las interacciones ocurren con el personal del museo, los docentes y los guías, estas personas pueden mejorar o inhibir las experiencias de aprendizaje de los visitantes.

El contexto social comprende los distintos niveles de relación interpersonal que se producen durante la visita. Abarca desde el núcleo más próximo hasta el más lejano del público visitante, los contactos con otras audiencias e incluso con el personal del museo. En este caso las variables de estudio se encuentran vinculadas a las relaciones interpersonales que se establecen durante la visita y que influyen para que la experiencia resultante sea diferente si se realiza acompañada por la familia, por un amigo o de manera independiente, si durante la misma se produjo una interacción grata con el personal del museo, o con otras personas, si se coincidió con grupos numerosos o si ese día el museo recibía pocas visitas (Falk y Dierking, 2000).

\subsubsection{El contexto físico}

El aprendizaje se produce en un ambiente específico que puede facilitar o no los comportamientos de quienes aprenden. El contexto físico incorpora el lugar donde está ubicado el museo, el entorno y sus alrededores, los elementos arquitectónicos que definen el espacio museístico, los objetos, la cartelería, el diseño de los lugares de exposición, el diseño del espacio interior, los estilos de enseñanza, el color y luz, los olores y la temperatura interior entre otros. Todas esta variables ejercen una influencia importante durante la visita a un museo y 
Revista de la Escuela de Ciencias de la Educación, año12, nRo.11, vol. 1, enero a Junio de 2016. PÁginas 79-98. ISSN 1851-6297. ISSN EN LINEA 2362-3349. DE PASEO POR UN MUSEO VIRTUAL. ApRENDIZAJeS Y VAloRACIONES DE estudiantes universitarios. María Fernanda Melgar - Analía Claudia Chiecher

sirven para personalizar la experiencia museística del público haciéndola diferente de otra. Falk y Dierking (2000) incluyen dentro del contexto físico factores como la orientación y los organizadores de avance, el diseño y el refuerzo de las experiencias fuera del museo.

Organización y orientación dentro del museo. Los museos suelen ser lugares grandes y resultan nuevos para los visitantes, tanto a nivel visual como auditivo. Cuando una persona se siente desorientada, necesita realizar mayores esfuerzos para poder aprender, de allí que la orientación colabora en el aprendizaje. Cuando un museo dispone de organizadores gráficos claros y conceptualmente precisos, la capacidad de las personas mejora significativamente para dar sentido a sus experiencias (Falk y Dierking, 2000; Hein, 1998).

El diseño. Tanto si se trata de exposiciones, programas o páginas Web, el aprendizaje está influido por el diseño. En los museos las exposiciones están diseñadas para que las personas puedan tener experiencias educativas interesantes. Las personas van a los museos para ver y experimentar con objetos reales situados en entornos apropiados. Los textos u ordenadores que se encuentran como recursos informativos no aportan nada por sí mismos, por ello es necesario diseñar exposiciones que estén pensadas para favorecer el aprendizaje (Falk y Dierking, 2000).

Refuerzo de las experiencias fuera del museo. El público asiste a los museos con conocimientos y se espera pueda construir otros nuevos que le sirvan para ser aplicados en su vida cotidiana. El conocimiento y la experiencia construida en el museo son incompletas, requieren de determinados entornos para convertirse en un todo. Con frecuencia, hechos y situaciones vividas en contextos externos al museo, semanas, meses o a menudo años después de la visita refuerzan la experiencia museística. El refuerzo de los aspectos aprendidos en la visita fuera del contexto del museo es un elemento clave del aprendizaje que ocurre dentro del museo (Falk y Dierking, 2000).

\section{Museos y TIC}

La relación entre los museos y las TIC se produce en varios sentidos. En general, las TIC aportan elementos diferentes a la experiencia con los museos. Pueden emplearse dentro de los museos y fuera de ellos.

Dentro de los museos, pueden emplearse en diferentes formatos como videos, audios y juegos, en exposiciones interactivas. Fuera del museo, como Apps, suelen utilizarse para descargar guías interactivas o diferentes recursos, también para emplear los Quick Response donde se amplía la información encontrada dentro del museo o el desarrollo de diferentes aplicaciones web que se descargan en el móvil y se pueden utilizar tanto dentro como fuera del museo. Este tipo de recursos suele ser empleado por adolescentes y jóvenes. 
Revista de la Escuela de Ciencias de la Educación, año 12, nRo.11, vol. 1, enero a junio de 2016. Páginas 79-98. ISSN 1851-6297. ISSN EN LÍNEA 2362-3349. DE PASEO POR UN MUSEO VIRTUAL. APRENDIZAJES Y VALORACIONES DE estudiantes universitarios. María Fernanda Melgar - Analia Claudia Chiecher

También las TIC se emplean para generar las web de los museos. Estos sitios suelen aportar información sobre la institución, las exposiciones que se van desarrollando así como las actividades que realizan. En general, la mayoría de los museos en la actualidad cuentan con un sitio web que ha generado un espacio destinado a educación que incluye recursos para emplear por las escuelas, juegos o actividades para realizar con la familia, antes, durante o después de la visita.

Los museos virtuales son otra de las relaciones posibles entre TIC y museos. En este artículo nos interesa este aspecto. Los museos virtuales constituyen contextos de aprendizaje novedosos con potencialidades de impactar en la formación de las personas en diversos sentidos. Son sitios web que constituyen entornos de aprendizaje vinculados al patrimonio cultural o natural, material o inmaterial, valorados y significados por diferentes grupos sociales que pueden tener o no un referente físico, y que colaboran en las funciones de conservación, investigación, exposición y divulgación -comunicación y educación- de los museos (Elisondo y Melgar, 2015).

En este sentido existen museos virtuales que tienen referentes físicos como el Google Cultural Institute (1), una iniciativa que recupera el patrimonio cultural y natural de diversas instituciones y países. También los museos virtuales pueden estar referidos a una única institución, por ejemplo las visitas virtuales a los Museos Vaticanos en donde es posible visitar la Capilla Sixtina (2) o la Basílica de San Pedro (3). La visita virtual al Smithsonian National Musuem of Natural History (4) o al Museo de Arte Latinoamericano de Buenos Aires (MALBA) (5). O bien los museos virtuales, pueden existir solamente en internet, como el Museo Virtual de Artes (6) (MUVA).

Los museos virtuales se configuran como entornos que estimulan diversas formas de aprender. En general, posibilitan el acceso colectivo a productos de la creación humana, el acceso gratuito de cualquier persona en todo momento y lugar evitando los gastos comprendidos en una visita a un museo físico; ofrecen oportunidades a quienes no podrían asistir a los museos físicos, por ejemplo a sujetos que sufren de alguna discapacidad motriz y pueden encontrar obstaculizada la visita. Además permiten trascender las limitaciones físicas del espacio y tiempo características de los museos tradicionales comprendiendo una nueva manera de organizar el contexto, conservar, resguardar y comunicar las colecciones. En algunos casos, sirven de medio para conocer las instalaciones de los museos físicos permitiendo planificar una visita futura (Bellido Gant 2001; Elisondo y Melgar, 2015; Sabattani, 2004).

Atendiendo a las potencialidades enunciadas de los museos virtuales como contextos de aprendizaje, en el siguiente apartado presentamos un estudio realizado con estudiantes universitarios. Intentamos identificar las concepciones de los jóvenes acerca de qué es un museo virtual así como los aspectos que destacan en la configuración de estos espacios como contextos 
Revista de la Escuela de Ciencias de la Educación, año12, NRO.11, vol. 1, enero a JUNio de 2016. Páginas 79-98. ISSN 1851-6297. ISSN EN LINEA 2362-3349. DE PASEO POR UN MUSEO VIRTUAL. ApRENDIZAJeS Y VAloRACIONES DE estudiantes universitarios. María Fernanda Melgar - Analía Claudia Chiecher

de aprendizaje. Específicamente, consideramos algunos elementos del Modelo Contextual del Aprendizaje, para analizar las experiencias de los estudiantes en museos virtuales.

\section{Estudio de experiencias en museos virtuales}

\subsection{Contexto de estudio, objetivos y procedimientos de recolección de datos}

El estudio se realizó considerando una propuesta educativa realizada con estudiantes universitarios. La propuesta invitaba a los estudiantes a visitar y explorar museos virtuales para luego dar respuesta, de manera grupal, a tres ítems en el marco de una tarea académica.

El objetivo general del estudio fue sondear concepciones sobre los museos virtuales en la perspectiva de los participantes así como identificar elementos que, desde su discurso, permitan caracterizar este espacio como un contexto para aprender.

Participaron de la experiencia 38 estudiantes (7) de la Licenciatura en Psicopedagogía de una Universidad Nacional de Argentina.

Para la recolección de datos se emplearon dos cuestionarios con preguntas abiertas y de respuesta individual. El primer cuestionario, cuya administración fue previa a la realización de la tarea sobre museos virtuales, se orientó a recoger las experiencias previas de los estudiantes en museos en general así como sus concepciones acerca de qué es un museo virtual y qué funciones tiene. Se obtuvieron respuestas de 26 estudiantes.

Una vez finalizada la tarea que implicaba la visita a museos virtuales, se administró un nuevo cuestionario, a fin de sondear diferentes aspectos de las visitas realizadas por los estudiantes a museos virtuales en el marco de la actividad solicitada. Así, luego de las visitas a museos virtuales, los estudiantes expresaban sus consideraciones acerca de los museos visitados en las dimensiones de contexto físico (¿Qué aspectos le ayudaron a navegar por la página? ¿Qué aspectos dificultaron la navegación? ¿Qué herramientas de las ofrecidas en el sitio le parecieron interesantes?), contexto social (¿Considera que los museos virtuales permiten relacionarse con otras personas? ¿Por qué? ¿Qué herramientas disponibles en los sitios web de los museos virtuales considera que posibilitan la relación con otros?) y contexto personal (¿Qué se puede aprender en un museo virtual? ¿Cómo se aprende en un museo virtual?). En este caso, se obtuvieron 38 respuestas del grupo de estudiantes.

Los dos cuestionarios administrados se conforman de preguntas abiertas y de respuesta libre. Por lo tanto, el análisis de los datos adopta una perspectiva cualitativa, a partir de la cual se construyen categorías sobre la base de las respuestas de los sujetos. 
Revista de la Escuela de Ciencias de la Educación, año 12, nRo.11, vol. 1, enero a Junio de 2016. Páginas 79-98. ISSN 1851-6297. ISSN EN LÍNEA 2362-3349. DE PASEO POR UN MUSEO VIRTUAL. APRENDIZAJeS Y VALORACIONES DE estudiantes universitarios. María Fernanda Melgar - Analia Claudia Chiecher

\subsection{Resultados del estudio}

El estudio de las experiencias educativas nos permitió identificar por un lado, concepciones de los estudiantes acerca de los museos virtuales y sus funciones y por otro, aspectos vinculados con sus percepciones de los museos virtuales como contextos educativos y de aprendizaje.

\subsubsection{Concepciones sobre museos virtuales y sus funciones}

Sobre la base de las respuestas de los estudiantes pueden identificarse al menos tres concepciones sobre museos virtuales. La primera y más común es aquella que considera a los museos virtuales como extensión de los físicos; la segunda, como espacios didácticos y de aprendizaje y la tercera como sitios vinculados al patrimonio.

Los museos virtuales como extensión de los físicos. La mayor parte del grupo (23 sujetos de 26) concibe a los museos virtuales como espacios, sitios, páginas web que valiéndose de las herramientas informáticas permiten conocer objetos (obras de arte, fotografías, documentos) de un museo físico. Su contenido está relacionado a la cultura. Su ventaja es que permiten conocer museos sin viajar y a cualquier hora del día. Transcribimos una respuesta de los estudiantes en el sentido mencionado:

Es un espacio que tiene la característica de utilizar los medios informáticos para cumplir con las finalidades de un museo tradicional además de posibilitar el acceso a sus bienes a todos aquellos que cuenten con una computadora, Tablet, etc. más allá de las distancias geográficas y de los horarios (LP).

Los museos virtuales como espacios didácticos y de aprendizaje. Solamente 2 sujetos expresaron concepciones de los museos virtuales como herramientas para aprender o enseñar. Una de las respuestas en el mencionado sentido fue la siguiente:

Un museo virtual es una herramienta didáctica de aprendizaje, se puede acceder desde cualquier computadora con internet y desde cualquier parte del mundo. Se puede conocer, explorar, investigar un lugar sin la necesidad de estar físicamente en el mismo (AU).

Los museos virtuales como sitios vinculados al patrimonio. Por fin, solamente 1 sujeto expresó una concepción de los museos virtuales como sitios en internet, cuya única especificidad es que tienen contenidos vinculados al patrimonio.

Pienso que es una oportunidad que nos brinda internet de tener acceso a lugares, y patrimonios antiguos y modernos (PR). 
Revista de la Escuela de Ciencias de la Educación, año12, nRo.11, vol. 1, enero a Junio de 2016. PÁginas 79-98. ISSN 1851-6297. ISSN EN LINEA 2362-3349. DE PASEO POR UN MUSEO VIRTUAL. ApRENDIZAJeS Y VAloRACIONES DE estudiantes universitarios. María Fernanda Melgar - Analía Claudia Chiecher

En relación con las funciones que tienen los museos virtuales pudimos identificar, a partir de las respuestas de los estudiantes, tres concepciones. La más frecuente fue que los museos virtuales sirven para aprender y educar (16 sujetos), luego que permiten conocer un museo físico (7 sujetos) y que tienen las mismas funciones que los físicos (3 sujetos).

Los museos virtuales sirven para aprender y educar. En este tipo de respuestas se percibe a los museos virtuales como espacios que educan, ofrecen oportunidades para aprender, informarse y explorar objetos y diferentes temas, también dan a conocer diferentes aspectos de la realidad.

Dar a conocer (de acuerdo a la temática de la que sea el museo), permite que, cualquier persona del mundo que tenga acceso a internet, pueda navegar por estos sitios sin tener que viajar (ya que muchas veces esto suele tener un gasto económico elevado el poder viajar a otro país, o lugar a conocer un museo). Nos permite aprender, investigar, entre otras funciones (FM).

Los museos virtuales sirven para dar a conocer museos físicos. En este tipo de respuestas los museos virtuales son concebidos como espacios que permiten promover la visita a museos físicos o darlos a conocer a la distancia. Es una concepción más cercana a lo que sería un sitio web de un museo, como espacio de promoción. No se advierte en esta concepción que los sujetos entiendan a los museos virtuales como espacios o contextos donde es posible aprender.

La primera función que desde todos partes del mundo cualquier personas con acceso a internet pueda conocer ese museo (RB)

Los museos virtuales tienen las mismas funciones que los físicos. En este tipo de respuestas se identifica que, los museos virtuales tienen las mismas funciones que los físicos; por ejemplo se encargan de investigar, conservar y educar sobre el patrimonio, historia, cultura, entre otros.

Las mismas que un museo tradicional, físico. Informar, conservar, enseñar, investigar, etc. También pueden funcionar como soporte al museo físico (LP).

Las concepciones más frecuentes en el grupo de estudiantes, aparecen ligadas a la idea de museos virtuales como extensión de los museos físicos. Resulta importante poder ampliar esta concepción ofreciendo museos virtuales que no tienen referentes físicos. También es frecuente que los conciban como espacios de aprendizaje y educación. Tal vez ello influenciado por su formación (son estudiantes de Psicopedagogía) y por el contexto en el que les fue solicitada la visita a los museos virtuales. En efecto, las visitas y la tarea a realizar a partir de ellas se solicitaron en el marco de una asignatura de la carrera. 
Revista de la Escuela de Ciencias de la Educación, año 12, nRo.11, vol. 1, enero a Junio de 2016. Páginas 79-98. ISSN 1851-6297. ISSN EN LÍNEA 2362-3349. DE PASEO POR UN MUSEO VIRTUAL. APRENDIZAJeS Y VALORACIONES DE estudiantes universitarios. María Fernanda Melgar - Analía Claudia Chiecher

\subsubsection{Percepciones de los museos virtuales como contextos educativos y de aprendizaje}

Tal como planteábamos en la sección inicial de este artículo, el MCA ofrece una propuesta para comprender las experiencias en museos físicos considerando la interacción del contexto físico - vinculado al ambiente -, el contexto social -relacionado a las interacciones con otros durante el proceso de aprender- y el contexto personal -vinculado a los intereses, motivaciones y conocimientos previos de las personas-. Teniendo en cuenta estas dimensiones teóricas se procuró caracterizar las experiencias en museos virtuales desde la perspectiva de los sujetos participantes.

\subsubsection{Percepciones sobre el contexto físico}

En esta categoría recogemos las percepciones de los estudiantes sobre el ambiente virtual, la estética del sitio web, el grado de accesibilidad, entre otros. Entre los aspectos que ayudaron a los estudiantes a navegar por la página se destacaron: la organización del sitio en tres grandes apartados o galerías (24 sujetos), el buscador interno (12 sujetos) y las imágenes, videos y audios (2 sujetos).

Organización del sitio en tres apartados principales. El Google Culture Institute presenta tres opciones definidas y organizadas claramente que permiten estructurar las visitas al sitio. En otro artículo nos hemos ocupado de la descripción del sitio (Elisondo y Melgar, 2015b). La organización presentada permite a las personas elegir qué recorridos desea realizar. Los estudiantes destacaron con una alta frecuencia (24) esta organización como favorecedora de la exploración del sitio.

Considero que la página está bien organizada, navegar por ella fue fácil ya que la misma está dividida en tres secciones y además posee un buscador para ir directamente a lo que queremos ver. Además se encuentran al inicio los contenidos más destacados (AU).

Buscador interno. Dentro de cada apartado existe un buscador que permite explorar el contenido por colección, ubicación, autor, fecha, entre otros. En este sentido, 12 estudiantes destacaron este aspecto como un elemento que facilitó la navegación por el sitio.

Los aspectos que me ayudaron navegar por la página son las herramientas de búsqueda como por ejemplo, fecha, creado por, soporte, evento, etc; la opción de "ordenar" también fue de gran utilidad (AC).

Imágenes, videos y audios. El contenido de cada apartado está expuesto recurriendo a múltiples soportes, entre los que se destacaron imágenes, videos y audios. Compartimos la respuesta de uno de los estudiantes que destacó este aspecto como favorecedor de la navegación por el sitio. 
Revista de la Escuela de Ciencias de la Educación, año12, nRo.11, vol. 1, enero a Junio de 2016. Páginas 79-98. ISSN 1851-6297. ISSN EN LINEA 2362-3349. DE PASEO POR UN MUSEO VIRTUAL. ApRENDIZAJeS Y VAloRACIONES DE estudiantes universitarios. María Fernanda Melgar - Analía Claudia Chiecher

Los aspectos que me ayudaron a navegar por la página son las imágenes, los videos, exposiciones, como así también la estructura de la misma, el poder explorar por autor, por año, por colecciones, etc. (LF).

En relación con los aspectos que obstaculizaron la visita, 17 estudiantes señalaron no haber encontrado obstáculos y aquellos que indicaron alguno mencionaron: el idioma (7 sujetos), la cantidad de información (5 sujetos), la velocidad de internet (5 sujetos) y otros aspectos (4 sujetos).

El idioma. La mayor cantidad de contenidos, principalmente en soporte de videos y audios se encuentran en inglés, de la misma manera que algunas colecciones en línea. Este aspecto actúa como un obstáculo importante limitando la elección de contenidos. En algunos contenidos existe la opción de traducción o subtítulos pero en otros no. Compartimos un respuesta de los estudiantes.

Que varios sitios se encontraban escritos en el idioma inglés (AC).

La cantidad de información. Cada apartado del Google Cultural Institute posee gran cantidad de información. Por ejemplo desde el Art Project es posible acceder a más de 700 colecciones en línea. La amplitud de opciones para algunas personas puede convertirse en oportunidades y para otras en obstáculos, por no saber qué elegir o por dónde comenzar la búsqueda. Algo parecido suele suceder en los museos físicos. Compartimos respuestas de los estudiantes.

Los aspectos que me dificultaron fue que no sabía cómo navegar a través de un museo, hay tanta variedad de información que uno no sabe por dónde empezar (AN).

La velocidad de la conexión a internet. En este tipo de respuestas los estudiantes señalaron que la velocidad con la que contaban para navegar por internet resultó "lenta" dado los soportes de contenidos (videos, audios e imágenes).

Creo que generalmente internet, por cuestiones de que anduvo lerdo y se dificultó poder navegar (FM).

Otros aspectos. En esta categoría residual se incluyeron respuestas referidas a dos aspectos. Por un lado, más que señalar un obstáculo, 3 sujetos realizan una crítica al sitio. Así, observaron una predominancia de contenidos referidos a países europeos y Estados Unidos y en menor medida de contenidos de América Latina. Por otro lado, 1 sujeto señaló como obstáculo la falta de competencias en la exploración de sitios web, que de alguna manera dificultaron su desempeño en esta tarea. Compartimos dos ejemplos de respuesta, el primero referido a la crítica sobre el contenido del sitio y el segundo sobre las escasas competencias en la navegación por sitios web. 
Revista de la Escuela de Ciencias de la Educación, año12, nRo.11, vol. 1, enero a Junio de 2016. Páginas 79-98. ISSN 1851-6297. ISSN EN LÍNEA 2362-3349. DE PASEO POR UN MUSEO VIRTUAL. APRENDIZAJeS Y VALORACIONES DE estudiantes universitarios. María Fernanda Melgar - Analia Claudia Chiecher

(..) No hay información de América Latina, una lástima (LP)

(...) No soy muy buena con la tecnología, y nunca navego demasiado (LA).

En relación con las herramientas ofrecidas por el sitio que resultaron interesantes para los estudiantes se destacaron las siguientes: imágenes, audios, documentos y videos (14), Street view (7), buscador interno (7), contenido (6) y otros (.4)

Imágenes, audios, documentos y videos. La exposición de contenidos empleando diversos soportes fue señalada como una de las herramientas interesantes en los museos virtuales. En este sentido, la exposición empleando diversos soportes permitiría generar experiencias holísticas que llegan a los visitantes por diversas puertas de entrada, en términos de Gardner (2005). Compartimos un ejemplo de respuesta.

Las herramientas que me parecieron interesantes fueron (...) las imágenes, los videos y audios que se convierten en los elementos que narran una historia (GB).

Street View. Esta herramienta permite que los usuarios de los museos virtuales puedan recorrer los sitios como si estuvieran en ellos de manera presencial. La herramienta proporciona panorámicas a nivel de calle (360 grados de movimiento horizontal y 290 grados de movimiento vertical), permitiendo a los usuarios ver partes de los museos, obras, lugares naturales, etc. Compartimos un ejemplo de respuesta.

Me pareció muy interesante la tecnología de Street view de Google que nos permite recorrer y mirar los diferentes lugares del mundo (GG).

Buscador interno. En este tipo de respuestas los participantes refirieron a las opciones de búsqueda en cada apartado. Específicamente algunos mencionaron herramientas como la de buscar según autores, ubicaciones y fechas o la posibilidad de ordenar los contenidos, por orden alfabético. Compartimos un ejemplo de respuesta.

Lo que más llamó mi atención y privilegio en este momento es el tema de los datos del autor, fecha, ubicación, y demás que ayudan a saber sobre el nivel de confiabilidad del sitio (JP).

Contenido. En este tipo de respuestas se destacaron aspectos como la variedad de contenidos y la fiabilidad de los mismos. Además se destacaron algunos en especial referidos a historia, arte, cultura, entre otros. Compartimos un ejemplo de respuesta. 
Revista de la Escuela de Ciencias de la Educación, año12, nRo.11, vol. 1, enero a Junio de 2016. PÁginas 79-98. ISSN 1851-6297. ISSN EN LINEA 2362-3349. DE PASEO POR UN MUSEO VIRTUAL. ApRENDIZAJeS Y VAloRACIONES DE estudiantes universitarios. María Fernanda Melgar - Analia Claudia Chiecher

Me pareció interesante que el sitio tenía muchísimas galerías para visitar y de variados temas. Esto es interesante para tener en cuenta a la hora de hacer trabajos académicos por ejemplo, ya que la información es muy confiable o también para informarse acerca de algún tema en particular $(\mathrm{JH})$.

Otros aspectos. En esta categoría reunimos aquellas respuestas en las que los sujetos indicaron herramientas con menor frecuencia. Dos participantes señalaron que todas las herramientas eran interesantes, sin especificar demasiado. Uno destacó el uso de redes sociales y otro la disposición de contenidos en diversos idiomas.

Todas, son sitios pensados, estudiados e implementados para el uso de cualquier tipo de usuario, su material resulta atractivo y las herramientas para acceder al mismo son las adecuadas (EM).

\subsubsection{Percepciones sobre el contexto social}

En esta categoría identificamos las percepciones de los estudiantes sobre las posibilidades de interactuar y aprender con otros que ofrecen los museos virtuales.

Frente a los interrogantes ¿considera que los museos virtuales permiten relacionarse con otras personas? y ¿por qué? los estudiantes respondieron 'Sí' (28), 'No' (7), 'No sé' (2) y 1 no respondió.

Del total de los que dijeron que sí, 5 no dieron argumento al respecto. De los restantes es posible identificar aspectos interesantes desde el punto de vista del aprendizaje. Destacaron como aspectos que favorecen el intercambio con otros la posibilidad de crear galerías de acceso público y abierto (11) y la posibilidad de compartir en redes sociales (5). Asimismo mencionaron que los museos virtuales podían permitir el intercambio con otros si se diseñaba una actividad de aprendizaje que promoviera las relaciones con otros, como en el caso que ellos habían experimentado (7).

Creación de galerías de acceso público. Existe una opción disponible para todos los contenidos que es la creación de galerías compuestas por diferentes colecciones que son de acceso público, lo que permite que cualquier persona pueda explorarlas. Esas galerías son creadas por usuarios comunes, sobre diferente temas y empleando variados soportes. La única limitación es que sólo pueden emplearse contenidos que están disponibles en la página. Compartimos las respuestas de algunos estudiantes.

Sí, ya que otros usuarios pueden acceder al museo y a las galerías creadas por otros y así también crear las propias (AU).

Compartir en redes sociales. Otro aspecto destacado, es la posibilidad de compartir contenidos por redes sociales. Por ejemplo las galerías 
Revista de la Escuela de Ciencias de la Educación, año12, nRo.11, vol. 1, enero a Junio de 2016. Páginas 79-98. ISSN 1851-6297. ISSN EN LÍNEA 2362-3349. DE PASEO POR UN MUSEO VIRTUAL. APRENDIZAJeS Y VALORACIONES DE estudiantes universitarios. María Fernanda Melgar - Analia Claudia Chiecher

creadas por los usuarios, audios, videos, etc. Compartimos un ejemplo de respuesta.

Creo que sí porque por el simple hecho de estar compartiendo una imagen o elemento del sitio en las redes, uno en estas redes está interaccionando con otras personas, lo cual, a esas personas puede interesarles y acceder al museo (...) (MB)

En el marco de una actividad de aprendizaje. En este tipo de respuestas, se señaló que los museos virtuales pueden permitir aprender y entablar relaciones, si son enmarcados dentro de una actividad de aprendizaje ofrecida por algún docente.

Creo que depende de la utilidad que le des a la navegación en el museo virtual, ya que si lo haces a través de una actividad como esta me parece que sí sirve para socializar con otras personas... (NM).

\subsubsection{Percepciones del contexto personal}

Las personas llegamos a los museos -tanto físicos como virtuales- con experiencias previas, intereses, expectativas y motivaciones. En esta dimensión consideramos las percepciones de los participantes sobre dos aspectos: qué se aprende en un museo virtual y cómo se aprende.

En relación a qué se aprende, se observaron tres tipos de respuestas frecuentes, que fueron clasificadas en categorías no excluyentes; esto es, un mismo sujeto podía dar una respuesta que correspondiera a más de una categoría. La mayoría señaló que se aprenden contenidos (26 sujetos), luego habilidades o competencias (11 sujetos) y por último experiencias (3 sujetos)

Contenidos. En este tipo de respuestas se mencionaron aspectos referidos a temas vinculados con la historia, arte, patrimonio. Asimismo refirieron a objetos, lugares, fechas, ubicaciones, fotografías, pinturas, etc.

Se puede aprender de todo, desde la cultura del lugar, las costumbres del sitio, idiomas, sobre arte, música, etc. es infinito el conocimiento que podemos generar a partir de la visita del lugar (RF).

Habilidades y competencias. En este tipo de respuestas los participantes mencionaron que los museos virtuales permiten aprender a explorar, buscar, comparar fuentes de información, investigar, entre otros.

Se aprende a explorar, a leer con más atención, a comparar fuentes de información, etc (MT).

Experiencias. Algunos participantes señalaron que los museos virtuales permiten tener experiencias diferentes, valorar contenido y compartir información con otros. 
Revista de la Escuela de Ciencias de la Educación, año12, nRo.11, vol. 1, enero a Junio de 2016. PÁginas 79-98. ISSN 1851-6297. ISSN EN LINEA 2362-3349. DE PASEO POR UN MUSEO VIRTUAL. ApRENDIZAJeS Y VAloRACIONES DE estudiantes universitarios. María Fernanda Melgar - Analia Claudia Chiecher

Creo que son diversos los aprendizajes que dejan este tipo de actividades. Desde conocer lugares asombrosos y estudiarlos en detalle accediendo a su historia antigua y moderna y a su ubicación, es decir, conocer de arte, de geografía, de cultura e historia hasta aprender a intercambiar con otros, saber sobre sus gustos, encontrarse uno mismo en el otro, descubrir que nos gustan cosas que pensamos que no nos gustaban, etc. (AG).

En relación a cómo se aprende, fue posible identificar las siguientes percepciones: leyendo, navegando, explorando, interactuando y experimentando (26 sujetos); con interés, predisposición, entusiasmo y tiempo ( 9 sujetos) y otros (5 sujetos). También en este caso las categorías no son excluyentes.

Navegando, explorando, interactuando. En las respuestas se enfatizaron aspectos relacionados al manejo de habilidades de alfabetización informacional. La web brinda demasiada cantidad de información, la selección y elección de contenidos requiere de explorar, interactuar, navegar, entre otras habilidades. Compartimos un ejemplo de respuesta.

Se aprende interactuando con la página web, recorriendo el sitio, explorando, experimentando y descubriendo cada espacio con interés y entusiasmo $(\mathrm{AU})$.

Con motivación e interés. En este tipo de respuestas, los participantes refieren a disposiciones a aprender, se aprende si dedicamos tiempo, esfuerzo, es decir, si nos comprometemos con las ganas de aprender. En definitiva, en estas respuestas existe una referencia a lo que puede entenderse como motivación intrínseca. Compartimos un ejemplo de este tipo de respuestas.

Claramente se aprende, primero por medio de la motivación (ya que si uno no tiene motivación el proceso no será fructífero), y en segundo lugar se aprende mediante la exploración (MT).

Otros. En este tipo de respuestas se señalaron aspectos relativos a que en los museos virtuales se aprende de manera autónoma, de un modo diferente a la educación formal y apelando a diferentes soportes (audios, imágenes, textos). Compartimos un ejemplo de respuesta.

Se aprende desde otra forma, desde otro lugar, que es virtual, que podemos explorar a cualquier hora del día (FM).

Aprender requiere compromiso en cualquier entorno y las experiencias en museos virtuales no quedan fuera de esta premisa. La dimensión de contexto personal permite visualizar que los participantes del estudio consideraron que se aprenden contenidos, pero también a través de estas experiencias se desarrollan habilidades y competencias informacionales, del mismo modo que se generan vivencias valiosas por diversos motivos. 
Revista de la Escuela de Ciencias de la Educación, año 12, nRo.11, vol. 1, enero a Junio de 2016. Páginas 79-98. ISSN 1851-6297. ISSN EN LÍNEA 2362-3349. DE PASEO POR UN MUSEO VIRTUAL. APRENDIZAJeS Y VALORACIONES DE estudiantes universitarios. María Fernanda Melgar - Analia Claudia Chiecher

\section{Consideraciones finales}

Las innovaciones en contextos de educación superior suelen ser desafiantes. No obstante, la Universidad como contexto de educación, no debería ocuparse únicamente de la formación en campos específicos; también debería ofrecer la posibilidad de acceder a nuevos espacios de aprendizaje. En este sentido, los museos representan espacios valiosos por diversas razones científicas, históricas, culturales, sociales, personales. En el presente estudio, hemos apostado a ir más allá de los museos físicos, proponiendo a un grupo de estudiantes universitarios un paseo por museos virtuales. Por medio del estudio de las experiencias de los estudiantes en estos contextos se han hallado resultados que nos plantean nuevos desafíos e implicancias educativas.

Más museos y más musas... Como veíamos en la sección de resultados, las concepciones más frecuentes de los participantes sobre los museos virtuales están asociadas directamente con los museos físicos. Así, estos espacios virtuales, son significados como extensiones de los tradicionales, que valiéndose de la tecnología permiten generar experiencias con objetos, imágenes, videos vinculados a la cultura. También ofrecen la posibilidad de conocerlos desde cualquier lugar del mundo y a cualquier hora. Por otro lado, son percibidos por los sujetos como espacios para aprender y educarse.

Atendiendo a los resultados hallados, en próximas implementaciones de propuestas que involucren visitas a museos virtuales resultaría oportuno ampliar la concepción que los sujetos tienen de ellos, mostrando museos virtuales sin referentes físicos y proponiendo paseos virtuales por estos espacios. También sería oportuno trabajar con museos argentinos que tienen referentes virtuales, ya que una de las críticas de los estudiantes fue que la mayor parte del contenido correspondía a países europeos. Los museo virtuales, pueden actuar como musas para nuevas experiencias...

Una segunda consideración que nos parece interesante realizar es la idea de ofrecer ocasiones para aprender. Compartimos con Bruner (1997) que la educación no es neutral e impacta en la identidad de la personas, en su autoestima y autoconcepto. Por eso, la educación tendría que permitirnos experimentar una variedad de propuestas diversas que incluyan el arte, la música, la literatura, la ciencia.

Los participantes percibieron a los museos virtuales como contextos de aprendizaje. En relación a la dimensión física destacaron elementos facilitadores del aprendizaje como la organización del sitio y las herramientas de búsqueda. Reconocieron para la experiencia el valor del uso de diferentes soportes (audios, videos, imágenes y textos) que le dan una característica singular.

Por otro lado, identificaron que existen ciertas herramientas que permiten interactuar y aprender con otros. Mencionaron la posibilidad de compartir en redes sociales y de crear galerías de acceso público. Por último, otro dato que queremos destacar, es que los estudiantes mencionaron que los museos 
Revista de la Escuela de Ciencias de la Educación, año12, nRo.11, vol. 1, enero a Junio de 2016. PÁginas 79-98. ISSN 1851-6297. ISSN EN LINEA 2362-3349. DE PASEO POR UN MUSEO VIRTUAL. ApRENDIZAJeS Y VAloRACIONES DE estudiantes universitarios. María Fernanda Melgar - Analía Claudia Chiecher

virtuales, esencialmente, se pueden convertir en espacios de aprendizaje social, si se propone su visita en el marco de una tarea de aprendizaje o de una asignatura en la universidad. Y este aspecto es importante porque nos desafía como docentes a no dejar de presentar ocasiones para aprender...

Finalmente, desde el punto de vista personal, los participantes consideraron que en los museos virtuales es posible aprender sobre contenidos variados pero también que estos permiten desarrollar competencias informacionales y tener experiencias que les ayudan a descubrir nuevos gustos o intereses. Este aspecto resulta relevante para desarrollar actividades de alfabetización informacional (Elisondo y Donolo, 2014).

Una tercera consideración refiere a la necesidad de seguir analizando las experiencias de los visitantes en museos virtuales. El modelo contextual del aprendizaje en museos ofrece dimensiones interesantes para analizar las experiencias museísticas. Sin embargo, sería necesario avanzar en nuevos aportes que consideren las características particulares de los entornos digitales.

En síntesis, las tecnologías habilitan espacios sin límites para aprender, difíciles de controlar y de circunscribir a ciertas fronteras, áreas y programas. Proponemos aumentar las oportunidades de aprender, diversificar los contextos en los que proponemos aprendizajes a los alumnos, ofrecer experiencias variadas, salir del aula, trascender sus muros.

Los procesos educativos no suceden solo en las aulas, sino que se expanden por múltiples y diversos espacios, presenciales y ahora también virtuales. Así, los museos virtuales representan excelentes ámbitos para generar aprendizajes de los más diversos.

\section{Notas Bibliográficas}

(1) Google Cultural Institute, disponible en https://www.google.com/culturalinstitute/ home?hl=es-419.

(2) Capilla Sixtina, disponible en http://www.vatican.va/various/cappelle/sistina_vr/index. $\mathrm{html}$

(3) Basílica de San Pedro, disponible en http://www.vatican.va/various/cappelle/sistina_vr/ index.html.

(4) Smithsonian National Musuem of Natural History, disponible en http://naturalhistory. si.edu/panoramas.

(5) Museo de Arte Latinoamericano de Buenos Aires (MALBA), disponible en http://www. malba.org.ar/recorrido-virtual.

(6) Museo Virtual de Artes, disponible en http://muva.elpais.com.uy/flash/muva. $\mathrm{htm}$ ?\&lang=en.

(7) La experiencia se está replicando actualmente con otros grupos de sujetos, con el fin de lograr mayor diversidad en las respuestas y ampliar la muestra. 
Revista de la Escuela de Ciencias de la Educación, año12, nRo.11, vol. 1, enero a Junio de 2016. Páginas 79-98. ISSN 1851-6297. ISSN EN LÍNEA 2362-3349. DE PASEO POR UN MUSEO VIRTUAL. APRENDIZAJES Y VALORACIONES DE estudiantes universitarios. María Fernanda Melgar - Analía Claudia Chiecher

\section{Referencias bibliográficas}

- $\quad$ Alderoqui, S. y Pedersoli, C. (2011). La educación en los museos. De los objetos a los visitantes. Buenos Aires: Editorial Paidós.

- $\quad$ Bellido Gant, M. L. (2001). Arte, museos y nuevas tecnologías. Gijon: Editorial TREA.

- Bruner, J. (1997). La educación puerta de la Cultura. Barcelona: Editorial Visor.

- Cole, M. (1999). Psicología cultural. Una disciplina del pasado y del futuro. Madrid: Editorial Morata.

- $\quad$ Elisondo, R. y Melgar, M. F. (2015). Museos y la Internet. Contextos para la innovación. Revista Innovación Educativa, 15 (68), 17-32. Recuperado el 11 de marzo de 2016 de http://www.innovacion.ipn.mx/Revistas/Documents/Revistas-2015/I-E-68/3-IE-68.pdf.

- Elisondo, R. y Donolo, D. (2014). Creatividad y Alfabetización Informacional. Revista Panorama, 8 (15), 23-33. Recuperado el 11 de marzo de 2016 de http://dialnet.unirioja. es/descarga/articulo/5051594.pdf.

- $\quad$ Elisondo, R., Donolo, D. y Rinaudo, M. (2009). Ocasiones para la creatividad en contextos de educación superior. Revista de Docencia Universitaria, (4), 1-16. Recuperado el 11 de marzo de 2016 de http://revistas.um.es/redu/article/view/92571.

- Falk, J. y Dierking, L. (2000). Learning from museums. Visitor experiences and the making of meaning. Estados Unidos: Ed. Altamira Press.

- Hein, G. (1998). Learning in the Museum. Estados Unidos y Canadá: Ed. Routledge.

- Hervás Avilés, R. M. (2010). Museos para la inclusión. Estrategias para favorecer experiencias interactivas. Revista Interuniversitaria de Formación del profesorado, (69), 150-124. Recuperado el 11 de marzo de 2016 de http://www.redalyc.org/articulo. oa? id=27419173008.

- Lemke, J. (2006). Investigación para el futuro de la educación científica: nuevas formas de aprender, nuevas formas de vivir. Enseñanza de las ciencias, 24 (1), 5-12.

- Perkins, D. (1993). La persona-más. Una visión distribuida del pensamiento y el aprendizaje. En Salomon, G. (Comp.) Cogniciones distribuidas. Consideraciones psicológicas y educativas. Buenos Aires: Editorial Amorrortu.

- Rennie, L. y Johnston D. (2004). The Nature of Learning and its Implications for Research on Learning from Museums. Science Education, (88), 4-16.

- Rennie, L. (2007). Learning Science Outside of School. En Abell, S. y Lederman, N. (Eds.). Handbook of research on science education. New Jersey: Ed. Lawrence Erlbaum Associates, Publishers.

- $\quad$ Rinaudo, M. (2014). Estudios sobre los contextos de aprendizaje: arenas y fronteras. En Paola Paoloni, María Cristina Rinaudo y Antonio González (Comps.), Cuestiones en Psicología Educacional. Perspectivas teóricas y metodológicas orientadas a la mejora de la práctica educativa (pp.163-206). La Laguna: Sociedad Latina de Comunicación Social. Recuperado de http://www.cuadernosartesanos.org/educacion.html.

- Sabattini, M. (2004). Museos y centros de ciencia virtuales. Complementación y potenciación del aprendizaje de ciencias a través de experimentos virtuales. Tesis Doctoral. Universidad de Salamanca. España. Recuperado el 11 de marzo de 2016 de http://www. sabbatini.com/marcelo/artigos/tesis-sabbatini.pdf.

- Sagástegui, S. (2004). Una apuesta por la cultura: el aprendizaje situado. Revista Electrónica Sinéctica, (24). Recuperado el 11 de marzo de 2016 http://portal.iteso.mx/ portal/page/portal/Sinectica/Historico/Numeros_anteriores05/024/24\%20Diana\%20 Sagastegui-Mapas.pdf. 